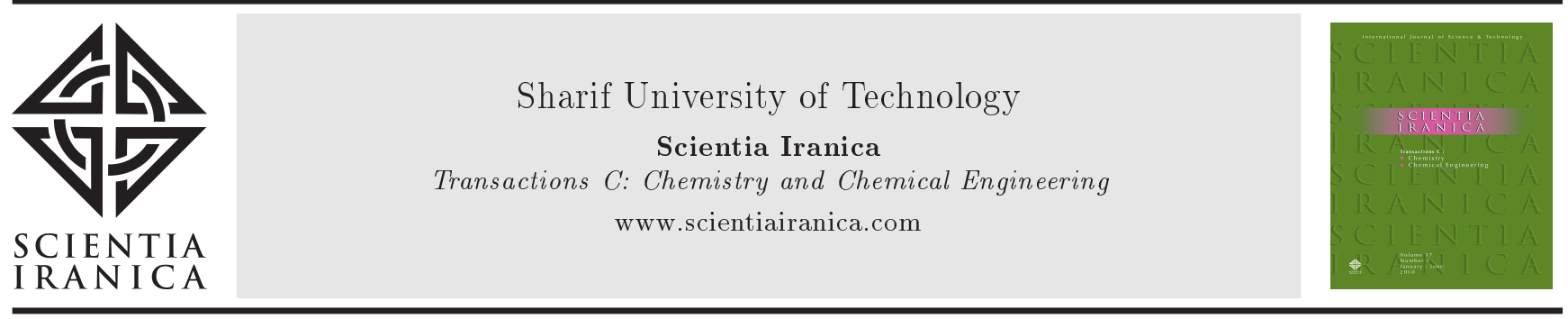

Research Note

\title{
Copper-catalyzed $N$-arylation of heterocycles in ethylene glycol medium
}

\author{
A. Sharifi*, M. Moazami, N. Ghonouei, M.S. Abaee and M. Mirzaei \\ Chemistry and Chemical Engineering Research Center of Iran, Tehran, P.O. Box 14335-186, Iran.
}

Received 26 June 2015; received in revised form 11 November 2015; accepted 10 May 2016

KEYWORDS
N-arylation;
Ethylene glycol;
Heterocycles;
Homogeneous
catalysis;
Microwave-assisted
synthesis.

\section{KEYWORDS}

$N$-arylation;

Homogeneous

Microwave-assisted

synthesis.

\begin{abstract}
N$-arylation of imidazole, benzimidazole, pyrazole, and indole was performed in the presence of $\mathrm{CuI}$ as the catalyst and $\mathrm{NaOH}$ as the base in ethylene glycol medium. Apparently, ethylene glycol played a dual role as both the reaction solvent and a ligand for the catalyst. All reactions proceed selectively to give the corresponding $N$-arylated products. In some cases, $O$-alkylation or dehalogenation was observed, which was explained by the proposed catalytic cycle. Conventional heating at $120^{\circ} \mathrm{C}$ and microwave irradiation both were used, where the results showed that microwave irradiation could facilitate the reaction by lowering the reaction times and increasing the yields. The reaction medium was recovered and reused in several consecutive runs.
\end{abstract}

(C) 2016 Sharif University of Technology. All rights reserved.

\section{Introduction}

$N$-Arylation of aromatic nitrogen in heterocyclic compounds is one of the most useful reaction types in medicinal chemistry [1] and natural products synthesis [2]. These heterocycles and their $N$-arylated products are the substructure of a variety of biologically [35] and pharmacologically [6,7] active substances. They have also found many applications in the chemistry of $N$-heterocyclic carbenes [8].

In the past two decades, copper-catalyzed Ullmann-type C-N couplings have been widely studied by different groups $[9,10]$. A variety of copper based catalysts, bases, and solvents have also been utilized to perform such reactions under milder conditions or in a ligand-free or solvent-free manner [11]. Application of green reaction media such as water [12] or ionic liquids [13] has also been reported. Despite all these breakthroughs, there is still a demand to adopt even simpler catalytic systems so that they involve low

\footnotetext{
*. Corresponding author. Tel.: +98 2144787749 ;

Fax: +982144787785

E-mail address: sharifi@ccerci.ac.ir (A. Sharifi)
}

catalyst loadings; proceed without the use of a ligand or at least use a simple, low-cost, and readily available ligand; run under milder conditions; and would preferably be recyclable.

Recently, there has been a rise in the application of glycols (Ethylene Glycol (EG) and polyethylene glycol (PEG)) and glycerol-derived solvents as media for organic syntheses due to their low toxicity, biodegradability, high boiling points, high chemical and thermal stability, low flammability, and the ability to dissolve both organic and inorganic compounds $[14,15]$. In this regard, these solvents have been used in $\mathrm{Cu}-$ catalyzed Ullmann-type C-N couplings. For instance, Huang reported amination of aryl iodides and bromides with aqueous ammonia using $\mathrm{CuSO}_{4}, \mathrm{Cs}_{2} \mathrm{CO}_{3}$, and sucrose as the ligand in PEG-200/water (1:1) [16]. Colasino and coworkers reported $N$-arylation of indole and benzimidazole in PEG-3400 under microwave irradiation at $150^{\circ} \mathrm{C}$. They used $10 \mathrm{~mol} \%$ of nano-sized $\mathrm{Cu}_{2} \mathrm{O}$ and two equivalents of $\mathrm{Cs}_{2} \mathrm{CO}_{3}$ as the base [17]. $N$-arylation of indoles has also been performed in glycerol at $120^{\circ} \mathrm{C}$ using CuI (10 mol\%) and DMSO [18]. Similarly, a ligand-free intramolecular C-N coupling to form benzotriazoles has been reported in PEG- 


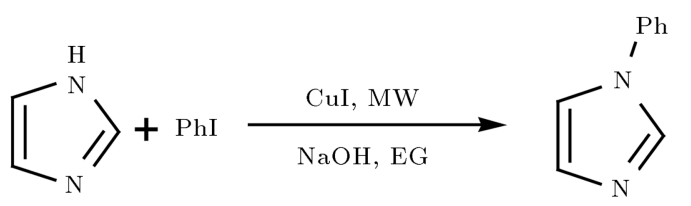

Scheme 1. Typical reaction pathway.

400/water (1:10) by using $\mathrm{CuI}(10 \mathrm{~mol} \%)$ and excess $\mathrm{K}_{2} \mathrm{CO}_{3}$ [19]. However, many of these reports are limited with the drawbacks such as the use of additional ligands, long reaction times, elevated temperatures, and low yields of products.

As far as we know, there are no reports for using neat EG in Cu-catalyzed $N$-arylation of aromatic nitrogens. Buchwald has reported a CuI-catalyzed reaction between primary or secondary amines with aryl iodides by using two equivalents of EG as the ligand in 2-propanol. Consequently, use of neat EG led to disadvantages such as high viscosity of the medium (even at $80^{\circ} \mathrm{C}$ ), low solubility of certain substrates in EG, and low yield of the products. Therefore, 2propanol was added to the system as the co-solvent [20]. In continuation of our studies on the development of environmentally benign synthetic procedures [21-23], hereby, we present EG as an efficient and recyclable medium for $N$-arylation of a variety of nitrogencontaining heterocycles with aryl iodides (and bromides) by using $\mathrm{CuI}$ as the catalyst and $\mathrm{NaOH}$ as the base (Scheme 1). The study suggests that EG plays a dual role as both the reaction solvent and a ligand for copper. All reaction components including the base and copper complexes are soluble in EG at the optimized temperature, providing the necessary conditions for a homogenous reaction.

\section{Material and methods}

\subsection{General}

All reagents and solvents were available commercially and used as received. Sodium hydroxide pellets from Merck Company were used. Progress of the reactions was monitored by TLC, using silica gel coated plates and EtOAc/petroleum ether mixture (1:1) as the eluent. Microwave-assisted reactions were carried out in a Milestone Microsynth ${ }^{\circledR}$ instrument. Melting points were uncorrected and obtained by Buchi Melting Point 530. ${ }^{1} \mathrm{H}$ NMR $(500 \mathrm{MHz})$ spectra were obtained on an FT-NMR Bruker Ultra Shield TM instrument in $\mathrm{CDCl}_{3}$ solutions; the chemical shifts are expressed as $\delta$ units with $\mathrm{Me}_{4} \mathrm{Si}$ as the internal standard. Gas chromatography-mass spectrometry was carried out on a Fisons GC 8000 gas chromatograph coupled to a Fisons TRIO 1000 mass spectrometer at ionization potential of $70 \mathrm{eV}$. All products were known and their identity was confirmed by the comparison of their melting points and their ${ }^{1} \mathrm{H}$ NMR data with those of authentic compounds available in the literature.

\subsection{General procedure for microwave-assisted CuI-catalyzed reactions of $\mathrm{N}$-heterocycles and aryl halides}

An aryl halide $(1.0 \mathrm{mmol})$ was added to a stirred mixture of an $N$-heterocycle $(2.0 \mathrm{mmol}), \mathrm{CuI}(0.05 \mathrm{mmol}$ for aryl iodides or $0.20 \mathrm{mmol}$ for aryl bromides), and $\mathrm{NaOH}(2.0 \mathrm{mmol})$ in ethylene glycol $(2.0 \mathrm{~mL})$. The reaction vessel was capped and placed in the microwave instrument and irradiated at $300 \mathrm{~W}$ for the time given in Table 2. After completion of the reaction, water $(30.0 \mathrm{~mL})$ was added to the mixture and the organic portion was extracted with ethyl acetate $(3 \times 5.0 \mathrm{~mL})$. The combined ethyl acetate layers were dried over $\mathrm{Na}_{2} \mathrm{SO}_{4}$ and evaporated under reduced pressure. The crude product was purified via a silica gel column using EtOAc/petroleum ether mixtures (1:1) as the eluent.

\subsection{General procedure for CuI-catalyzed reaction of $N$-heterocycles and aryl halides under conventional heating}

Aryl halide $(1.0 \mathrm{mmol})$ was added to a stirred mixture of an $N$-heterocycle $(2.0 \mathrm{mmol})$, CuI (0.05 mmol for aryl iodides or $0.20 \mathrm{mmol}$ for aryl bromides), and $\mathrm{NaOH}(2.0 \mathrm{mmol})$ in ethylene glycol $(2.0 \mathrm{~mL})$. The reaction vessel was capped and stirred magnetically in a preheated oil bath at $120^{\circ} \mathrm{C}$ for 24 hours. After completion of the reaction, water $(30.0 \mathrm{~mL})$ was added to the mixture and the organic portion was extracted with ethyl acetate $(3 \times 5.0 \mathrm{~mL})$. The combined ethyl acetate layers were dried over $\mathrm{Na}_{2} \mathrm{SO}_{4}$ and evaporated under reduced pressure. The crude product was purified via a silica gel column using EtOAc/petroleum ether mixtures $(1: 1)$ as the eluent.

\section{Results and discussion}

We first optimized a model reaction between imidazole and iodobenzene by examining different sets of conditions. The results are summarized in Table 1.

By using $20 \mathrm{~mol} \% \mathrm{CuI}$ and two equivalents of $\mathrm{NaOH}$, the conversion of the reactants to the target product (1a) at $100^{\circ} \mathrm{C}$ was only $50 \%$ after 24 hours (entry 1). The yield increased to $90 \%$ after 24 hours at $120^{\circ} \mathrm{C}$ (entry 2). Search in the literature showed that microwave irradiation could facilitate Ullmann-type reactions [24]. Thus, we repeated the reaction under microwave irradiation. After 1.5 hours of irradiation at $50 \mathrm{~W}$, only $30 \%$ conversion to the desired product was noticed (entry 3). However, higher microwave powers gave better results within the same time (entries 4-5).

Then, we examined the effect of different $\mathrm{Cu}(\mathrm{I})$ salts on the progress of the reaction (entries 6-8). This led to comparable results within similar time periods and, therefore, $\mathrm{CuI}$ remained the catalyst of choice due 
Table 1. Optimization of the reaction conditions.

\begin{tabular}{ccclllcc}
\hline Entry & Imidazole: $\mathbf{P h X}$ & $\mathbf{X}$ & $\mathbf{C u}(\mathbf{I})(\mathbf{m o l} \%)$ & $\mathbf{B a s e}^{\mathbf{a}}$ & Conditions & Time (h) & Yield (\%) $^{\mathbf{b}}$ \\
\hline 1 & $2: 1$ & $\mathrm{I}$ & $\mathrm{CuI}(20)$ & $\mathrm{NaOH}$ & $10{ }^{\circ} \mathrm{C}$ & 24 & 50 \\
2 & $2: 1$ & $\mathrm{I}$ & $\mathrm{CuI}(20)$ & $\mathrm{NaOH}$ & $120^{\circ} \mathrm{C}$ & 24 & 90 \\
3 & $2: 1$ & $\mathrm{I}$ & $\mathrm{CuI}(20)$ & $\mathrm{NaOH}$ & $\mathrm{MW}, 50 \mathrm{~W}$ & 1.5 & 30 \\
4 & $2: 1$ & $\mathrm{I}$ & $\mathrm{CuI}(20)$ & $\mathrm{NaOH}$ & $\mathrm{MW}, 150 \mathrm{~W}$ & 1.5 & 50 \\
5 & $2: 1$ & $\mathrm{I}$ & $\mathrm{CuI}(20)$ & $\mathrm{NaOH}$ & $\mathrm{MW}, 300 \mathrm{~W}$ & 1.5 & 95 \\
6 & $2: 1$ & $\mathrm{I}$ & $\mathrm{CuCl}(20)$ & $\mathrm{NaOH}$ & $\mathrm{MW}, 300 \mathrm{~W}$ & 1.5 & 90 \\
7 & $2: 1$ & $\mathrm{I}$ & $\mathrm{CuBr}(20)$ & $\mathrm{NaOH}$ & $\mathrm{MW}, 300 \mathrm{~W}$ & 1.5 & 85 \\
8 & $2: 1$ & $\mathrm{I}$ & $\mathrm{CuCN}(20)$ & $\mathrm{NaOH}$ & $\mathrm{MW}, 300 \mathrm{~W}$ & 1.5 & 80 \\
9 & $2: 1$ & $\mathrm{I}$ & $\mathrm{CuI}(10)$ & $\mathrm{NaOH}$ & $\mathrm{MW}, 300 \mathrm{~W}$ & 1.5 & 95 \\
10 & $2: 1$ & $\mathrm{I}$ & $\mathrm{CuI}(5)$ & $\mathrm{NaOH}$ & $\mathrm{MW}, 300 \mathrm{~W}$ & 1.5 & 95 \\
11 & $2: 1$ & $\mathrm{Br}$ & $\mathrm{CuI}(20)$ & $\mathrm{NaOH}$ & $\mathrm{MW}, 300 \mathrm{~W}$ & 3 & 80 \\
12 & $2: 1$ & $\mathrm{Cl}$ & $\mathrm{CuI}(20)$ & $\mathrm{NaOH}$ & $\mathrm{MW}, 300 \mathrm{~W}$ & 3 & 5 \\
13 & $1: 1$ & $\mathrm{I}$ & $\mathrm{CuI}(5)$ & $\mathrm{NaOH}$ & $\mathrm{MW}, 300 \mathrm{~W}$ & 1.5 & 70 \\
14 & $1: 1.2$ & $\mathrm{I}$ & $\mathrm{CuI}(5)$ & $\mathrm{NaOH}$ & $\mathrm{MW}, 300 \mathrm{~W}$ & 1.5 & 65 \\
15 & $2: 1$ & $\mathrm{I}$ & $\mathrm{CuI}(5)$ & $\mathrm{NaOH}$ & $\mathrm{MW}, 300 \mathrm{~W}$ & 1.5 & 70 \\
16 & $2: 1$ & $\mathrm{I}$ & $\mathrm{CuI}(5)$ & $\mathrm{K}{ }_{3} \mathrm{PO}$ & $\mathrm{MW}, 300 \mathrm{~W}$ & 1.5 & 90 \\
17 & $2: 1$ & $\mathrm{I}$ & $\mathrm{CuI}(5)$ & $\mathrm{Cs}_{2} \mathrm{CO}{ }_{3}$ & $\mathrm{MW}, 300 \mathrm{~W}$ & 1.5 & 93 \\
\hline
\end{tabular}

a: 2.0 Equivalents of base; ${ }^{b}$ : GC yields; ${ }^{c}$ : 1.5 Equivalents of base.

to its lower cost. Catalytic amounts of $\mathrm{CuI}$ as low as $5 \mathrm{~mol} \%$ were enough for the reactions with iodobenzene (entries 9-10), while more loading (20 mol\%) was necessary in the case of bromobenzene (entry 11). Aryl chlorides did not react under any conditions (entry 12). Alteration of the molar ratio of imidazole to iodobenzene (entries 13-14) or decreasing the amount of the base (entry 15) only led to lower yields of the product. Replacing $\mathrm{NaOH}$ with other bases such as $\mathrm{K}_{3} \mathrm{PO}_{4}$ or $\mathrm{Cs}_{2} \mathrm{CO}_{3}$, which are more common in $\mathrm{Cu}-$ catalyzed reactions, did not improve the results (entries 16-17).

We next studied the generality of the procedure by applying the optimized conditions (Table 1, entry 10 for ArI and entry 11 for ArBr) to the reactions of some other nitrogen-heterocycles with different aryl halides. The results are shown in Table 2. As it is obvious from the table, imidazole reacts more readily with iodobenzene than indole, pyrazole, and benzimidazole do (entries 1-3), perhaps due to the greater nucleophilicity and solubility of the former one in the reaction medium $[25,26]$. Substitution pattern on the aryl halide did not interfere with the results and para-substituted aryl halides as well as meta- and ortho- derivatives were utilized equally well. Aryl bromides also reacted under these conditions (entries 9-12), but they needed more catalyst loading, and still the reaction times were fairly longer. To highlight the effect of microwave irradiation on the yield and the time, some of the reactions were performed under both the conventional heating at $120^{\circ} \mathrm{C}$ and microwave conditions. With microwave irradiation, reactions were complete in reasonably shorter time periods and gave good to excellent yields of the products.

When pyrrole was reacted with iodobenzene ( $\mathrm{Ta}-$ ble 3 , entry 1), formation of both 1-phenylpyrrole and 2-phenoxy ethanol was observed. Competitive $N$ and $O$-alkylation in $\mathrm{Cu}$-catalyzed reactions has been previously observed and discussed in several reports [9]. A reaction cycle to rationalize this observation is proposed in Scheme 2 [33]. The first step is the coordination of nucleophile with $\mathrm{Cu}$. The coordinated nitrogen atom is then deprotonated in the presence of the base. The preference for $N$-alkylation is the result of the greater nucleophilicity of the nitrogen of the reactant as opposed to that of the oxygen
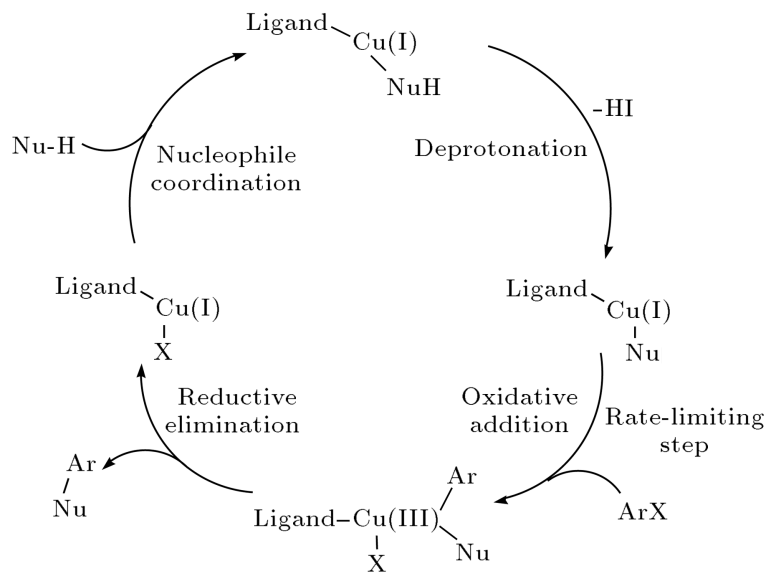

Scheme 2. General reaction mechanism. 
A. Sharifi et al./Scientia Iranica, Transactions C: Chemistry and ... 23 (2016) 2742-2749

Table 2. Reactions of aryl halides with different nitrogen-heterocycles.

\begin{tabular}{|c|c|c|c|c|c|}
\hline Entry & ArX & Product & $\begin{array}{c}\text { Time }(\mathrm{h}) / \\
\text { yield }(\%)^{\mathrm{a}} \\
(\mathrm{MW})\end{array}$ & $\begin{array}{l}\text { Time }(\mathrm{h}) / \\
\text { yield }(\%) \\
\text { (thermal) }\end{array}$ & $\begin{array}{c}\mathrm{Mp}\left({ }^{\circ} \mathrm{C}\right) \\
\text { Found/literature }\end{array}$ \\
\hline 1 & & & $1.5 / 95$ & $24 / 80$ & $50-52 / 54-55$ [27] \\
\hline 2 & & & $2 / 83$ & $24 / 50$ & oil/oil [28] \\
\hline 3 & & & $2 / 70$ & $24 / 40$ & 88-90/94-95 [29] \\
\hline 4 & & & $3 / 60$ & $24 / 40$ & oil/oil [29] \\
\hline 5 & & & $3 / 95$ & $24 / 10^{\mathrm{b}}$ & $52-55 / 56-57[30]$ \\
\hline 6 & & & $2 / 80$ & $24 / 10^{\mathrm{b}}$ & $33-35 / 33-35$ [29] \\
\hline 7 & & & $3 / 80$ & $24 / 30$ & $28-30 / 28-30$ [29] \\
\hline 8 & & & $2 / 91$ & $-/-$ & oil/oil [31] \\
\hline $9^{c}$ & & & $4 / 80$ & $24 / 70$ & $123-124 / 122-124$ [32] \\
\hline $10^{c}$ & & & $4 / 90$ & $-/-$ & oil/oil [12] \\
\hline $11^{\mathrm{c}}$ & & & $4 / 80$ & $-/-$ & $50-52 / 54-55$ [27] \\
\hline
\end{tabular}

a: Isolated yields; ${ }^{b}:$ GC yields; $^{c}$ : CuI (20 mol\%). 
Table 2. Reactions of aryl halides with different nitrogen-heterocycles (continued).

\begin{tabular}{lccccc}
\hline Entry ArX & Product & $\begin{array}{c}\text { Time (h)/ } \\
\text { yield (\%) } \\
(\mathbf{M W})\end{array}$ & $\begin{array}{c}\text { Time (h)/ } \\
\text { yield (\%) } \\
(\text { thermal) }\end{array}$ & $\begin{array}{c}\text { Mp }\left({ }^{\circ} \mathbf{C}\right) \\
\text { Found /literature }\end{array}$ \\
\hline $12^{\mathrm{C}}$ & & & & \\
\hline
\end{tabular}

a: Isolated yields; b: GC yields; ${ }^{c}$ : $\mathrm{CuI}(20 \mathrm{~mol} \%)$.

Table 3. Competitive formation of $O$-arylated and dehalogenated byproducts.

\begin{tabular}{|c|c|c|c|c|c|}
\hline $\operatorname{Entry}^{a}$ & Reactant & $\begin{array}{c}\text { ArI } \\
\text { conversion (\%) }\end{array}$ & $\begin{array}{c}N \text {-Arylation } \\
\text { yield }(\%)\end{array}$ & $\begin{array}{c}O \text {-Arylation }{ }^{\mathrm{b}} \\
\text { yield }(\%)\end{array}$ & $\begin{array}{c}\text { Dehalogenation }^{b} \\
\text { yield (\%) }\end{array}$ \\
\hline 1 & 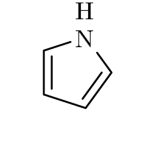 & $100 \%$ & $28 \%$ & $72 \%$ & $0 \%$ \\
\hline 2 & $\mathrm{~N}^{\prime}$ & $82 \%$ & $\begin{array}{l}-\mathrm{N}^{\prime} \\
0 \%\end{array}$ & $34 \%$ & $66 \%$ \\
\hline 3 & & $100 \%$ & $24 \%$ & $50 \%$ & $26 \%$ \\
\hline
\end{tabular}

a: Reaction conditions: heterocycle $(2.0 \mathrm{mmol})$, aryl halide $(1.0 \mathrm{mmol}), \mathrm{CuI}(5 \mathrm{~mol} \%), \mathrm{NaOH}(2.0 \mathrm{mmol})$, EG $\left(2.0 \mathrm{~cm}^{3}\right)$, MW (300 W), 1h;

b: Confirmed by GC-Mass analysis.

of ethylene glycol and the rate-limiting step is the oxidative addition of the aryl halide to copper. In the case of pyrrole, because of low nucleophilicity of nitrogen, deprotonation must occur first and thus ethylene glycol (in excess) is bound to copper faster and it continues the cycle [34].

For aryl halides with an electron-withdrawing substituent such as a nitro group, a different cycle (Scheme 3) [33] may be suggested to account for the observed results (Table 3 , entry 2 ). In this case, the oxidative addition of the electron deficient aryl halide is fast and occurs as the first step of the process followed by rate-limiting addition of ethylene glycol to form complex 1. Complex 1 may then either undergo a reductive elimination to form the arylated ethylene glycol side product or give a dehalogenated product via a $\beta$ hydride elimination $[35,36]$. The dehalogenated product can also be traced in the reaction of pyrrole with 4 -iodotoluene (entry 3), which confirms the formation of complex 1 in the reaction cycle. Finally, to evaluate the reactivity of the saturated heterocycles under the optimized conditions, the reaction of pyrrolidine with iodobenzene was tried, where $O$-arylation occurred as the major reaction and only a very low formation of the target compound was noticed.

The model reaction between imidazole and 4iodoanisole was also used to evaluate the recoverability of the catalyst. After each reaction, the product was extracted with diethyl ether. Then, the reaction medium was recovered by removing the volatile portion under reduced pressure and reused successfully in the next several runs without further addition of the base or $\mathrm{CuI}$. The results are summarized in Table 4 .

Table 4. Recovery of the catalyst system.

\begin{tabular}{ccc}
\hline Entry & Run & Yield $(\boldsymbol{\%})^{\mathbf{a}}$ \\
\hline 1 & 1st & 95 \\
2 & 2nd & 90 \\
3 & 3rd & 90 \\
4 & 4 th & 80 \\
5 & 5 th & 50 \\
\hline
\end{tabular}

a: GC yields. 


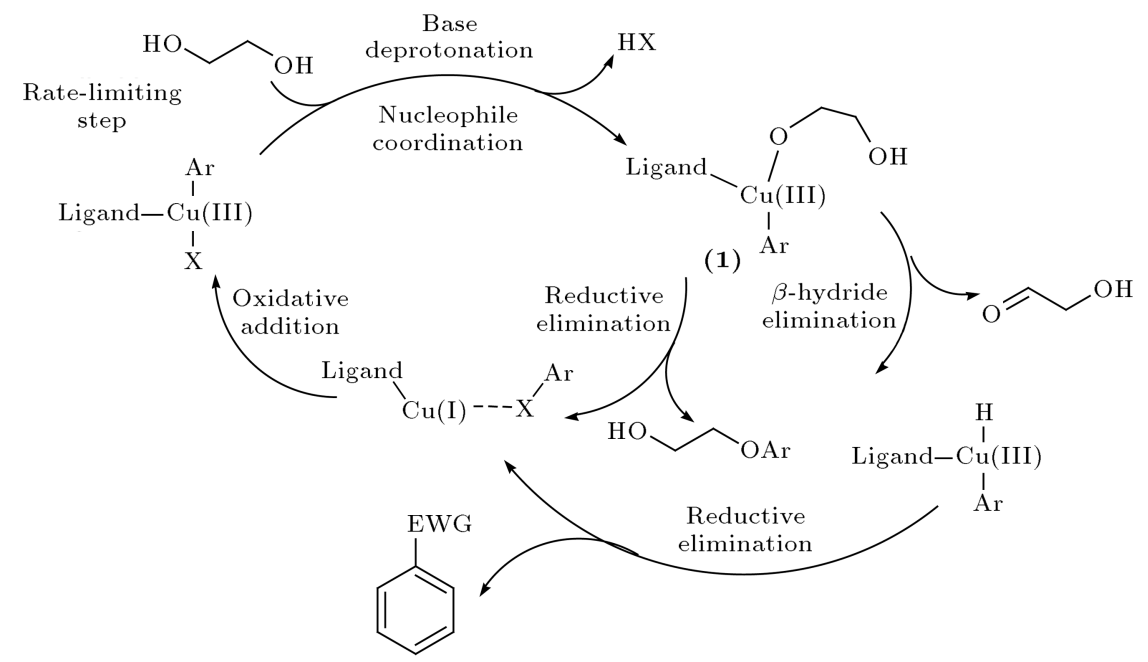

Scheme 3. Formation of arylated ethylene glycol and dehalogenation.

\section{Conclusion}

In summary, we have introduced ethylene glycol as an efficient medium for $\mathrm{Cu}(\mathrm{I})$-catalyzed reaction of aryl iodides and bromides with nitrogen-heterocycles under both thermal and microwave conditions. The catalyst system is inexpensive and readily available, and it can be recovered and reused successfully in several runs.

\section{Acknowledgements}

The Grant Council at CCERCI is gratefully acknowledged for financial support of this work.

\section{References}

1. Evano, G., Theunissen, C. and Pradal, A. "Impact of copper-catalyzed cross-coupling reactions in natural product synthesis: the emergence of new retrosynthetic paradigms", Nat. Prod. Rep., 30(12), pp. 1467-1489 (2013).

2. Roughley, S.D. and Jordan, A.M. "The medicinal chemist's toolbox: an analysis of reactions used in the pursuit of drug candidates", J. Med. Chem., 54(10), pp. 3451-3479 (2011).

3. Finn, J., Mattia, K., Morytko, M., Ram, S., Yang, Y., Wu, X., Mak, E., Gallant, P. and Keith, D. "Discovery of a potent and selective series of pyrazole bacterial methionyl-tRNA synthetase inhibitors", Bioorg. Med. Chem. Lett., 13(13), pp. 2231-2234 (2003).

4. Wiglenda, T., Ott, I., Kircher, B., Schumacher, P., Schuster, D., Langer, T. and Gust, R. "Synthesis and pharmacological evaluation of $1 H$-imidazoles as ligands for the estrogen receptor and cytotoxic inhibitors of the cyclooxygenase", J. Med. Chem., 48(20), pp. 6516-6521 (2005).

5. Wiglenda, T. and Gust, R. "Structure-activity relationship study to understand the estrogen receptordependent gene activation of aryl- and alkyl- substituted $1 H$-imidazoles", J. Med. Chem., 50(7), pp. 1475-1484 (2007).

6. Zhong, J. "Muscarine, imidazole, oxazole and thiazole alkaloids", Nat. Prod. Rep., 22(2), pp. 196-229 (2005).

7. O'Hagan, D. "Pyrrole, pyrrolidine, pyridine, piperidine and tropane alkaloids", Nat. Prod. Rep., 17(5), pp. 435-446 (2000).

8. Ranganath, K.V.S., Onitsuka, S., Kumar, A.K. and Inanaga, J. "Recent progress of N-heterocyclic carbenes in heterogeneous catalysis", Catal. Sci. Technol., 3(9), pp. 2161-2181 (2013).

9. Sambiagio, C., Marsden, S.P., Blacker, A.J. and McGowan, P.C. "Copper catalysed Ullmann type chemistry: from mechanistic aspects to modern development", Chem. Soc. Rev., 43(10), pp. 3525-3550 (2014).

10. Rao, H. and Fu, H. "Copper-catalyzed coupling reactions", Synlett, 22(6), pp. 745-769 (2011).

11. Monnier, F. and Taillefer, M. "Catalytic C-C, C-N, and C-O Ullmann-type coupling reactions", Angew. Chem. Int. Ed., 48(38), pp. 6954-6971 (2009).

12. Wang, D., Zhang, F., Kuang, D., Yua, J. and Lia, J. "A highly efficient $\mathrm{Cu}$-catalyst system for $\mathrm{N}$-arylation of azoles in water", Green Chem., 14(5), pp. 1268-1271 (2012).

13. Yan, J.C.Y., Zhou, L. and Wang, L. "Amination reactions of aryl halides with nitrogen-containing reagents catalyzed by $\mathrm{CuI}$ in ionic liquid", Chin. J. Chem., 26(1), pp. 165-169 (2008).

14. Yue, H., Zhao Y., Ma, X. and Gong, J. "Ethylene glycol: properties, synthesis, and applications", Chem. Soc. Rev., 41(11), pp. 4218-4244 (2012).

15. Gu, Y. and Jerome, F. "Glycerol as a sustainable solvent for green chemistry", Green Chem., 12(7), pp. 1127-1138 (2010).

16. Huang, M., Wang, L., Zhu, X., Mao, Z., Kuang, D. and Wan, Y. "Amination of aryl halides by using an environmentally benign, recyclable copper catalyst", Eur. J. Org. Chem., 26, pp. 4897-4901 (2012). 
17. Colacino, E., Villebrun, L., Martinez, J. and Lamaty, F. "PEG3400- $\mathrm{Cu}_{2} \mathrm{O}-\mathrm{Cs}_{2} \mathrm{CO}_{3}$ : an efficient and recyclable microwave-enhanced catalytic system for ligandfree Ullmann arylation of indole and benzimidazole", Tetrahedron, 66(21), pp. 3730-3735 (2010).

18. Yadav, D.K.T., Rajak, S.S. and Bhanage, B.M. "Narylation of indoles with aryl halides using copper/glycerol as a mild and highly efficient recyclable catalytic system", Tetrahedron Lett., 55(4), pp. 931935 (2014).

19. Mukhopadhyay, C., Tapaswi, P.K. and Butcher, R.J. "A ligand-free copper(I) catalysed intramolecular $N$ arylation of diazoaminobenzenes in PEG-water: an expeditious protocol towards regiospecific 1-aryl benzotriazoles", Org. Biomol. Chem., 8(20), pp. 4720-4729 (2010).

20. Kwong, F.Y., Klapars, A. and Buchwald, S.L. "Copper-catalyzed coupling of alkylamines and aryl iodides: An efficient system even in an air atmosphere", Org. Lett., 4(4), pp. 581-584 (2002).

21. Sharifi, A., Abaee, M.S., Rouzgard, M. and Mirzaei, M. "Ionic liquid $[\mathrm{bmim}]\left[\mathrm{NO}_{3}\right]$, an efficient medium for green and one-pot synthesis of benzothiazinones at room-temperature", Sci. Iran, 20(3), pp. 555-560 (2013).

22. Sharifi, A., Barazandeh, M., Abaee, M.S. and Mirzaei, M. " $[\mathrm{Omim}]\left[\mathrm{BF}_{4}\right]$, a green and recyclable ionic liquid medium for the one-pot chemoselective synthesis of benzoxazinones", Tetrahedron Lett., 51(14), pp. 18521855 (2010).

23. Sharifi, A., Abaee, M.S., Rouzgard, M. and Mirzaei, M. "Ionic liquid [omim] $\left[\mathrm{NO}_{3}\right]$, a green medium for room temperature synthesis of benzothiazinone derivatives in one pot", Green Chem. Lett. Rev., 5(4), pp. 649-698 (2012).

24. Liu, Z.J., Vors, J.P., Gesing, E.R.F. and Bolm, C. "Microwave-assisted solvent- and ligand-free coppercatalysed cross-coupling between halopyridines and nitrogen nucleophiles", Green Chem., 13(1), pp. 42-45 (2011).

25. Baidya, M., Brotzel, F. and Mayr, H. "Nucleophilicities and Lewis basicities of imidazoles, benzimidazoles, and benzotriazoles", Org. Biomol. Chem., 8(8), pp. 1929-1935 (2010).

26. Denmark, S.E., Organic Reactions, 85, John Wiley \& Sons, New York (2014).

27. Gong, C., Liye, H., Huacan, S., Li, S., Yiqian, W., Jinlong, W. and Xinhai, Z. "A facile and efficient oxalyldihydrazide/ketone-promoted copper-catalyzed amination of aryl halides in water", Eur. J. Org. Chem., 5, pp. 635-642 (2009).

28. Hosseinzadeh, R., Tajbakhsh, M., Alikarami, M. and Mohadjerani, M. " $N$-arylation of N-H heterocycles with aryl bromides and aryl iodides using $\mathrm{CuI}$ and $\mathrm{KF} / \mathrm{Al}_{2} \mathrm{O}_{3}$ ", J. Heterocyclic Chem., 45(6), pp. 18151818 (2008).

29. Wang, Y., Yang, Q., Zhang, M. and Lin, D. "Narylation of heterocycles catalyzed by activated-copper in pure water", Tetrahedron Lett., 54(15), pp. 19941997 (2013).

30. Allolio, C., Meyer, D., Peritz, A., Schul, T., Strassner, T. and Ahrens, S. "Electronic effects of parasubstitution on the melting points of TAAILs", Chem. Asian J., 6, pp. 863-867 (2011).

31. Hosseinzadeh, R., Tajbakhsh, M. and Alikarami, M. "Highly efficient copper-catalyzed formation of N-aryl diazoles using $\mathrm{KF} / \mathrm{Al}_{2} \mathrm{O}_{3}$ ", Synlett, 17(13), pp. 21242126 (2006).

32. Alakonda, L. and Periasamy, M. "Simple and convenient methods for $N$-arylation of heterocycles and diphenylamine", Synthesis, 44(7), pp. 1063-1068 (2012).

33. Yu, H.Z., Jiang, Y.Y., Fu, Y. and Liu, L. "Alternative mechanistic explanation for ligand-dependent selectivities in copper-catalyzed $N$ - and $O$-arylation reactions", J. Am. Chem. Soc., 132(51), pp. 18078-18091 (2010).

34. Liu, Y., Park, S.K., Xia, Y. and Chae, J. "Copper(II)catalyzed C-O coupling of aryl bromides with aliphatic diols: synthesis of ethers, phenols, and benzo-fused cyclic ethers", Org. Biomol. Chem., 12(26), pp. 47474753 (2014).

35. Cannon, K.A., Geuther, M.E., Kelly, C.K., Lin, S. and Macarthur, A.H.R. "Hydrodehalogenation of aryl chlorides and aryl bromides using a microwaveassisted, copper-catalyzed concurrent tandem catalysis methodology", Organometallics, 30(15), pp. 4067-4073 (2011).

36. Jenk, C.J., Xi, M., Yang, M.X. and Bent, B.E. "Kinetics and energetics of $\beta$-hydride elimination on $\mathrm{Cu}(100)$ : determining the copper-alkyl bond energy", J. Phys. Chem., 98(8), pp. 2152-2157 (1994).

\section{Biographies}

Ali Sharifi obtained his BS and MS degrees from Shiraz University, Shiraz, Iran, and then PhD degree from Sharif University of Technology, including a six-month research project at the Institute of Organic Chemistry of Justus- Liebig University, Giessen, Germany, in 1995. He is currently Associate Professor in the Faculty of Organic Chemistry and Natural Products at the Chemistry and Chemical Engineering Research Center of Iran (CCERCI). His research interests include new methodologies in organic synthesis, green chemistry, and medicinal chemistry.

Maryam Moazami obtained her BS degree from Alzahra University in 2013 and her MS degree from the Chemistry and Chemical Engineering Research Center 
of Iran (CCERCI) under the supervision of Dr. Ali Sharifi.

Nima Ghonouei obtained his BS and MS degrees from Sharif University of Technology. He is currently a $\mathrm{PhD}$ candidate at the Chemistry and Chemical Engineering Research Center of Iran (CCERCI) under the supervision of Dr. Ali Sharifi.

Mohammad Saeed Abaee obtained his MS degree from University of Tehran, Iran, and $\mathrm{PhD}$ degree from the University of Saskatchewan, Canada, in 1999. He is currently Professor of Organic Chemistry in the Faculty of Organic Chemistry and Natural Products at the Chemistry and Chemical Engineering Research Center of Iran (CCERCI). His research interests include the study of Lewis acid catalyzed reactions, thiopyran chemistry, and environmental chemistry.

Mojtaba Mirzaei obtained his BS degree from Tabriz University in 1997 and his MS degree from the Chemistry and Chemical Engineering Research Center of Iran (CCERCI), Tehran, Iran. He is currently a PhD candidate at University of Tehran, Iran. 